THE ECONOMIC INTEGRATION OF EUROPE 



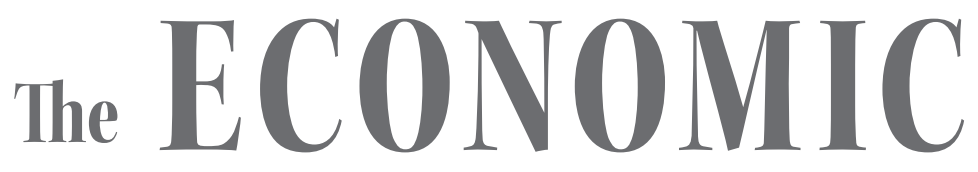

INTEGRATION

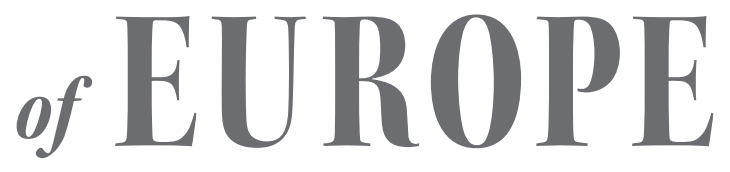

\title{
RICHARD POMFRET
}

\author{
III \\ II \\ Harvard University Press \\ Cambridge, Massachusetts | London, England 2021
}


Copyright (C) 2021 by the President and Fellows of Harvard College

ALL RIGHTS RESERVED

Printed in the United States of America

First printing

Cover photographs: Creativ Studio Heinemann

Cover design by Lisa Roberts

$$
\begin{gathered}
9780674259430 \text { (EPUB) } \\
9780674259454 \text { (PDF) }
\end{gathered}
$$

The Library of Congress has cataloged the printed edition as follows:

Names: Pomfret, Richard W. T., author.

Title: The economic integration of Europe / Richard Pomfret.

Description: Cambridge, Massachusetts : Harvard University Press, 2021. | Includes bibliographical references and index.

Identifiers: LCCN 2020048892 | ISBN 9780674244139 (hardcover)

Subjects: LCSH: European Union. | Europe-Economic integration. |

European Union countries-Economic conditions. | Europe- Economic conditions-1945-

Classification: LCC HC241 .P663 2021 | DDC 337.1/42—dc23

LC record available at https://lccn.loc.gov/2020048892 